\title{
Pituitary sex hormones enhance the pro-metastatic potential of human lung cancer cells by downregulating the intracellular expression of heme oxygenase-1
}

\author{
AHMED ABDELBASET-ISMAIL ${ }^{1,2}$, DANIEL PEDZIWIATR ${ }^{1}$, GABRIELA SCHNEIDER $^{1}$, JACEK NIKLINSKI $^{3}$, \\ RADOSLAW CHARKIEWICZ ${ }^{3}$, MARCIN MONIUSZKO ${ }^{4}$, MAGDA KUCIA $^{1,5}$ and MARIUSZ Z. RATAJCZAK ${ }^{1,5}$ \\ ${ }^{1}$ Stem Cell Institute at James Graham Brown Cancer Center, University of Louisville, Louisville, KY, USA; \\ ${ }^{2}$ Department of Surgery, Anesthesiology and Radiology, Faculty of Veterinary Medicine, Zagazig University, Zagazig, \\ Egypt; Departments of ${ }^{3}$ Clinical Molecular Biology and ${ }^{4}$ Regenerative Medicine and Immune Regulation, \\ Medical University of Bialystok, Bialystok; ${ }^{5}$ Department of Regenerative Medicine, \\ Warsaw Medical University, Warsaw, Poland
}

Received July 13, 2016; Accepted September 9, 2016

DOI: 10.3892/ijo_xxxxxxxx

\begin{abstract}
We report that human lung cancer cell lines express functional receptors for pituitary sex hormones (SexHs) and respond to stimulation by follicle-stimulating hormone (FSH), luteinizing hormone (LH), and prolactin (PRL). Expression of these receptors has also been confirmed in patient lung cancer samples at the mRNA level. Stimulation of human lung cancer cell lines with FSH, LH, or PRL stimulated migration and chemotaxis, and some cell lines responded by enhanced proliferation. Moreover, priming of human lung cancer cells by exposing them to pituitary SexHs resulted in enhanced seeding efficiency of injected human lung cancer cells into bone marrow, liver, and lungs in an immunodeficient mouse model. The chemotaxis of lung cancer cell lines corresponded with the activity of heme oxygenase-1 (HO-1), as stimulation of these cells by FSH, LH, and PRL downregulated its expression in a p38 MAPK-dependent manner. Moreover, while downregulation of $\mathrm{HO}-1$ by the small-molecule inhibitor tin protoporphyrin ( $\mathrm{SnPP}$ ) promoted migration, upregulation of HO-1 by the small-molecule activator cobalt protoporphyrin (CoPP) showed the opposite effect. Based on this finding, we propose that pituitary SexHs play a significant role in the pathogenesis of lung cancer, particularly when the blood level of FSH increases due to gonadal dysfunction with advanced age. Finally, we propose that upregulation of HO-1 expression by a small-molecule activator may be effective in controlling SexH-induced cell migration in lung cancer.
\end{abstract}

Correspondence to: Professor Mariusz Z. Ratajczak, Stem Cell Institute at James Graham Brown Cancer Center, University of Louisville, 500 S. Floyd Street, Rm. 107, Louisville, KY 40202, USA E-mail: mzrata01@louisville.edu

Key words: lung cancer, metastasis heme oxygenase-1, folliclestimulating hormone, luteinizing hormone, prolactin

\section{Introduction}

Evidence has accumulated that sex hormones (SexHs) play a role in the development and progression of several malignancies arising in the gonads (1), urogenital tract (2-4), breast (5), skeletal muscles (6) and hemato/lymphohematopoietic tissues (7). Gonadal SexHs, and in particular pituitary SexHs such as follicle-stimulating hormone (FSH), luteinizing hormone ( $\mathrm{LH})$, and prolactin (PRL), are potent mitogens, and their enhanced level in peripheral blood (PB) is associated with prostate, colon, and lung cancer (8-11). Based on this evidence, we became interested in the potential role of pituitary SexHs in lung carcinoma and employed four non-small cell lung cancer (NSCLC) cell lines (A549, HTB177, HTB183, and CRL5803) and two small cell lung cancer (SCLC) cell lines (CRL2062 and CRL5853) to investigate this possible linkage. We also studied tissue samples from lung cancer patients. An additional reason to pursue this question is the fact that the level of FSH increases with age as a result of aging and gradual dysfunction of the gonads $(12,13)$. This increase could be linked to an increase in certain malignancies, including lung cancer, in the aged population (14).

Lung cancer is the number one cause of cancer-related deaths in industrialized countries (15) and is expected to cause $\sim 200,000$ and $\sim 350,000$ deaths yearly, respectively, in the United States and European Union alone. These statistics are undoubtedly related to the prevalence of cigarette smoking and air pollution (16). The four major histological types of bronchial carcinoma are squamous cell carcinoma, adenocarcinoma, large cell undifferentiated carcinoma, and small cell carcinoma, and the first three can be grouped in the category termed NSCLC to distinguish them from SCLC. SCLC is more common in men than in women and is strongly associated with cigarette smoking (17) and, in contrast to NSCLC, is derived from the neuroendocrine cells of the lung, which are characterized by the expression of neuron-specific enolase, neurosecretory granules, and neurofilaments and the ability to secrete a host of polypeptide hormones $(18,19)$. These tumors 
are composed of small, dark, round-to-oval, lymphocyte-like cells (albeit larger than lymphocytes) that have scant cytoplasm and hyperchromatic nuclei (20). SCLCs are rapidly growing lesions that tend to infiltrate widely and metastasize early in the course of the disease and therefore are rarely resectable.

Migration and metastasis of cancer cells is orchestrated by several signaling pathways involved in the change of cell shape, and two major theories have been proposed to explain their migration. The first, the so-called cytoskeletal model, postulates a rapid polymerization of actin and formation of actin filaments at the cell's leading edge, with a supportive role of microtubules at the retracting trailing edge (21). The second somewhat competitive membrane flow model, postulates extension of the leading edge by addition of membrane at the front of the cell and endocytosis of integrins toward the rear of the cell (22). We have recently demonstrated that heme oxygenase-1 (HO-1) is a potent inhibitor of hematopoietic cell migration and that downregulation of HO-1 enhances the migration of cells, while its overexpression has the opposite effect $(23,24)$.

Here, we demonstrate that human lung cancer cell lines as well as primary tumor samples express pituitary $\mathrm{SexH}$ receptors. These receptors are functional and may promote migration, adhesion, and proliferation of lung cancer cells. Moreover, priming of human lung cancer cells by pituitary SexHs resulted in enhanced seeding efficiency of injected human cells to bone marrow, liver, and lungs in an immunodeficient mouse model. Finally, the enhanced chemotaxis of human lung cancer cells after stimulation by FSH, LH, and PRL corresponded with downregulation of HO-1 activity in a p38 MAPK-dependent manner, which suggests that modulating $\mathrm{HO}-1$ activity could be of therapeutic value.

\section{Materials and methods}

Cell lines. We used several human lung cancer cell lines (obtained from ATCC) including four NSCLC cell lines (A549, HTB177, HTB183, and CRL5803) and two SCLC cell lines (CRL2062 and CRL5853). All NSCLC cell lines were cultured in Roswell Park Memorial Institute (RPMI)-1640 medium containing L-glutamine (GE Healthcare) and 10\% heat-inactivated fetal bovine serum (FBS; VWR Life Science Seradigm). Waymouth's MB 752/1 medium containing 10\% FBS, was used for cultivation of CRL2062 cells. CRL5853 cells were maintained in DMEM/F12 medium supplemented with 5\% FBS, $5 \mu \mathrm{g} / \mathrm{ml}$ insulin, $0.005 \mathrm{mg} / \mathrm{ml}$ transferrin, $30 \mathrm{nmol} / 1$ sodium selenite (ITS; Lonza, Inc., Allendale, NJ, USA), 10 nmol/1 hydrocortisone, $10 \mathrm{nmol} / 1 \beta$-estradiol (both from Sigma-Aldrich, St. Louis, MO, USA), and $4 \mathrm{mmol} / \mathrm{l} \mathrm{L-glutamine.} \mathrm{Penicillin}$ (100 U/ml), and streptomycin (10 $\mu \mathrm{g} / \mathrm{ml}$; Corning) were added to all types of media. These cells were cultured in a humidified atmosphere of $5 \% \mathrm{CO}_{2}$ at $37^{\circ} \mathrm{C}$ with change of medium every $48 \mathrm{~h}$. In some experiments, the human ovarian cancer cell line A2780 was cultured in RPMI-1640 medium with 10\% FBS under the same atmospheric conditions.

Human lung cancer samples. Lung cancer samples from eight patients suffering from NSCLC were obtained during surgery after informed consent according to the institutional IRB protocol, and the cDNA was extracted for mRNA analysis.
Reverse transcription-polymerase chain reaction ( $R T-P C R)$. Total RNA was purified from NSCLC and SCLC cells as well as primary lung cancer patients $(n=8)$ using the RNeasy Mini kit after treatment with DNase I (both from Qiagen, Inc.). The purified mRNA was afterwards reverse-transcribed into cDNA using TaqMan Reverse Transcription Reagents (Applied Biosystems/Life Technologies, Foster City, CA, USA). Amplification of synthesized cDNA fragments was carried out using AmpliTaq Gold DNA Polymerase (Applied Biosystems/Life Technologies). The PCR conditions used were 1 cycle of $8 \mathrm{~min}$ at $95^{\circ} \mathrm{C} ; 2$ cycles of $2 \mathrm{~min}$ at $95^{\circ} \mathrm{C}$, $1 \mathrm{~min}$ at $60^{\circ} \mathrm{C}$, and $1 \mathrm{~min}$ at $72^{\circ} \mathrm{C} ; 40$ cycles of $30 \mathrm{sec}$ at $95^{\circ} \mathrm{C}$, $1 \mathrm{~min}$ at $60^{\circ} \mathrm{C}$, and $1 \mathrm{~min}$ at $72^{\circ} \mathrm{C}$; and 1 cycle of $10 \mathrm{~min}$ at $72^{\circ} \mathrm{C}$. The sequence-specific primers employed for amplification were as follows: human follicle-stimulating hormone receptor (hFSHR; sense, 5'-gcttctgagatctgtggaggtt-3' and antisense, 5'-ggacaaacctcagttcaatggc-3'), human luteinizing hormone/choriogonadotropin receptor (hLHCGR; sense, 5'-ccggtctcactcgactatcac-3' and antisense, 5'-tgaggaggttgtcaaaggca-3'), human prolactin receptor (hPRLR; sense, 5'-ctgggctttctgccttactca-3' and antisense, 5'-ttctttagttttgccagggagca- $\left.3^{\prime}\right)$. Samples without template controls and reverse transcriptase were used in each run. All primers were designed using the NCBI/Primer-BLAST program, and at least one primer included an exon-intron boundary. Afterwards, all PCR products were analyzed by $2 \%$ agarose gel electrophoresis.

Transwell migration assay. After cells were enzymatically dissociated using $0.25 \%$ trypsin and rendered quiescent by incubation in appropriate pre-warmed medium supplemented with $0.5 \%$ (NSCLCs) or $0.2 \%$ (SCLCs) bovine serum albumin (BSA; Sigma-Aldrich) at $37^{\circ} \mathrm{C}$, they were seeded onto the upper chambers of $1 \%$ gelatin-coated Transwell inserts containing polycarbonate membranes with an $8-\mu \mathrm{m}$ pore size (Costar Transwell; Corning Costar, Lowell, MA, USA). The lower Boyden chambers received different concentrations of FSH (0.01-10 mU/ml), LH $(0.01-10 \mathrm{mU} / \mathrm{ml})$, or PRL $(0.05-5 \mu \mathrm{g} / \mathrm{ml})$ in serum-free assay medium $(650 \mu \mathrm{l})$. All of these reagents were purchased from Prospec-Tany TechnoGene, Ltd. (East Brunswick, NJ, USA). The lower chambers containing $10 \%$ FBS and $0.5 \%$ or $0.2 \%$ BSA in appropriate medium served as positive and negative controls, respectively. After a 24-h stimulation at $37^{\circ} \mathrm{C}$, the upper chambers were carefully removed, the cells that had not migrated were removed with a cotton applicator swab from the upper side, and the cells that had transmigrated to the lower side of the membrane were fixed and stained with Hema 3 reagent (PROTOCOL; Thermo Fisher Scientific, Pittsburgh, PA, USA) and then counted using an inverted microscope. In some experiments, the CRL2062 cell line was also evaluated for cell migration toward these SexHs after inhibition or stimulation of HO-1. The cells were exposed to the small-molecule HO-1 inhibitor tin protoporphyrin (SnPP) IX dichloride $(50 \mu \mathrm{mol} / \mathrm{l})$, the HO-1 activator cobalt protoporphyrin (CoPP) IX chloride $(50 \mu \mathrm{mol} / \mathrm{l})$ (both from Tocris Bioscience), or vehicle alone for $2 \mathrm{~h}$ in serum-free medium. Two hours later, all these cells were washed with PBS and evaluated for migration toward FSH, LH, PRL, or medium alone. The loaded inserts were afterwards carefully removed, and the migrated cells were stained and counted $24 \mathrm{~h}$ post-loading. The results are presented as a chemotactic 
ratio (the number of cells that migrated toward the medium containing test reagents/the number of cells that migrated toward the medium alone $\mathrm{x} 100$ ).

Signal transduction studies. Quiescent cells were stimulated with $0.5 \%$ BSA in RPMI-1640 medium, FSH (1 mU/ml), LH $(1 \mathrm{mU} / \mathrm{ml})$, or PRL $(0.5 \mu \mathrm{g} / \mathrm{ml})$ for $5 \mathrm{~min}$ at $37^{\circ} \mathrm{C}$. Harvested cells were then washed with PBS, treated with RIPA lysis buffer supplemented with protease and phosphatase inhibitors (Santa Cruz Biotechnology, Inc.) for $30 \mathrm{~min}$ on ice, and centrifuged at $15,000 \mathrm{rpm}$ at $-4^{\circ} \mathrm{C}$ for $15 \mathrm{~min}$. The protein concentration was measured using the Pierce BCA Protein Assay kit (Pierce Biotechnology, Inc., Rockford, IL, USA) and Multimode Analysis Software (Beckman Coulter). The concentration-adjusted extracted proteins were then separated on a 4-12\% SDS-PAGE gel and transferred to a PVDF membrane (Bio-Rad). All membranes were blocked with $2.5 \%$ BSA in Tris-buffered saline containing $0.1 \%$ Tween (TBST) for $1 \mathrm{~h}$ at room temperature. After washing with TBST, phosphorylation of the intracellular kinase p42/44 mitogen-activated protein kinase (p42/44 MAPK), p38 MAPK, and AKT was detected by incubating the membranes overnight at $4^{\circ} \mathrm{C}$ with phospho-specific anti-phospho-p42/44 MAPK (clone no. 9101, diluted at 1:1,000), anti-phospho-AKT (Ser473; clone no. 9271, diluted at 1:1,000) rabbit polyclonal antibodies, and anti-phospho-p38 MAPK (Thr180/Thr182; clone no. 9216, diluted at 1:2,000) mouse monoclonal antibody (Cell Signaling Technology, Inc.). Next, the PVDF membranes were incubated with horseradish peroxidase (HRP)-conjugated goat anti-rabbit or anti-mouse IgG secondary antibodies (1:5,000; Santa Cruz Biotechnology, Inc.) for $2 \mathrm{~h}$ at RT. To confirm equal protein loading in all lanes, the blots were stripped using stripping buffer (Thermo Fisher Scientific) and then reprobed with appropriate anti-rabbit p42/44 MAPK (clone no. 9102), anti-rabbit p38 MAPK (clone no. 9212), and anti-rabbit AKT (clone no. 9272) antibodies (all from Cell Signaling Technology, Inc.). All membranes were then treated with enhanced chemiluminescence (ECL) reagent and subsequently exposed to film (Hyperfilm) (both from Amersham/GE Healthcare Life Sciences). For band visualization, an automatic film developer supplied with fresh warm developer and fixer solutions was used.

Expression of HO-1 by western blot analysis. Cells (CRL5853, CRL2062) were cultured with FSH (1 mU/ml), LH (1 mU/ml), or PRL $(0.5 \mu \mathrm{g} / \mathrm{ml})$ in serum-free RPMI-1640 medium for $6 \mathrm{~h}$ at $37^{\circ} \mathrm{C}$. The harvested cells were centrifuged and washed with ice-cold PBS. The total protein extracts were collected, and their concentrations were then measured. The concentration-adjusted extracted proteins (70 $\mu \mathrm{g} /$ each sample) were then separated on a 4-12\% SDS-PAGE gel and then transferred to a PVDF membrane. Next, the membranes were blocked with $2.5 \%$ non-fat dry milk in Tris-buffered saline containing $0.1 \%$ Tween (TBST) for $1 \mathrm{~h}$ at room temperature. After washing with TBST, the membranes were incubated with rabbit anti-HO-1 polyclonal antibody (diluted at 1:1,000; Enzo Life Sciences, Inc., Farmingdale, NY, USA) overnight at $4^{\circ} \mathrm{C}$. To assure equal protein loading in all the lanes, the blots were then reprobed with rabbit anti- $\beta$-actin monoclonal antibody (diluted at 1:1,000; Novus Biologicals, Littleton, CO, USA). All membranes were treated with ECL reagent, and subsequently exposed to film for band visualization.

Adhesion of human lung cancer cells to fibronectin. Quiescent cells were incubated for $5 \mathrm{~h}$ in $0.5 \%$ BSA RPMI-1640 medium in a humidified atmosphere of $5 \% \mathrm{CO}_{2}$ at $37^{\circ} \mathrm{C}$. Next, NSCLC (A549, HTB177) and SCLC (CRL2062, CRL5853) cell lines were cultured in $0.5 \%$ BSA RPMI-1640 medium, or with FSH $(1-10 \mathrm{mU} / \mathrm{ml}), \mathrm{LH}(1-10 \mathrm{mU} / \mathrm{ml})$, or PRL $(0.05-5 \mu \mathrm{g} / \mathrm{ml})$ in medium containing BSA for a 5 -min incubation at $37^{\circ} \mathrm{C}$. Cells were then added directly and allowed to adhere to the fibronectin-coated wells (5,000 cells/well) in 96-well plates at $37^{\circ} \mathrm{C}$. The wells were coated first with $70 \mu \mathrm{l}$ of fibronectin $\left(10 \mu \mathrm{g} / \mathrm{ml}\right.$; Sigma-Aldrich) overnight at $4^{\circ} \mathrm{C}$ and blocked before the experiment with BSA for $2 \mathrm{~h}$ at $37^{\circ} \mathrm{C}$. Following incubation of unstimulated and stimulated cells at $37^{\circ} \mathrm{C}$, the plates were vigorously washed three times with PBS, and the adherent cells were counted under an inverted microscope. The results are presented as an adhesion ratio (the number of adherent cells stimulated with SexHs/the number of adherent unstimulated cells x100).

Cell proliferation. Cells were cultured in 24-well plates (CELLSTAR; Greiner Bio-One) in RPMI-1640 culture medium containing $0.5 \%$ (NSCLCs) or $0.2 \%$ (SCLCs) BSA for $72 \mathrm{~h}$ at an initial density of $1.25 \times 10^{4}$ cells/well (NSCLCs) or $6 \times 10^{4}$ cells/well (SCLCs) in the presence or absence of FSH (1 mU/ml), LH (1 mU/ml), or PRL $(0.5 \mu \mathrm{g} / \mathrm{ml})$. RPMI-1640 medium containing $0.5 \%$ or $0.2 \%$ BSA was used as a negative control, while the full medium containing $10 \%$ FBS was treated as a positive control. The cell number was calculated directly after cell seeding $(0 \mathrm{~h})$ as well as 24,48 , and $72 \mathrm{~h}$ after addition of the stimulants. At these time points, the cells were harvested from the wells and counted using FACS.

Quantitative real-time PCR (RT-qPCR). RT-qPCR was performed to detect and quantify relative levels of HO-1 mRNA in human lung cancer cells stimulated in vitro with FSH (1 mU/ml), LH (1 mU/ml), or PRL $(0.5 \mu \mathrm{g} / \mathrm{ml})$ in serum-free medium for $6 \mathrm{~h}$ at $37^{\circ} \mathrm{C}$. The purified RNA was reverse-transcribed with MultiScribe Reverse Transcriptase, oligo(dT), and a random hexamer primer mix (all from Applied Biosystems/Life Technologies). Quantitative evaluation of the target gene was then performed by using an ABI PRISM 7500 Sequence Detection System (Applied Biosystems/Life Technologies) with Power SYBR-Green PCR Master Mix reagent and specific primers (hHO-1 sense, 5'-gggtgatagaagaggccaagact-3' and antisense, 5'-agctcctgcaactcctcaaga-3'). The PCR cycling conditions were $95^{\circ} \mathrm{C}(15 \mathrm{sec}), 40$ cycles at $95^{\circ} \mathrm{C}(15 \mathrm{sec})$, and $60^{\circ} \mathrm{C}(1 \mathrm{~min})$. According to the melting point analysis, only one $\mathrm{PCR}$ product was amplified under these conditions. The relative quantity of a target gene, normalized to the $\beta 2$-microglobulin gene as the endogenous control and relative to a calibrator, was expressed as $2^{-\Delta \Delta \mathrm{Ct}}$ (fold difference), where $\mathrm{Ct}$ is the threshold cycle, $\Delta \mathrm{Ct}=(\mathrm{Ct}$ of target genes $)-(\mathrm{Ct}$ of the endogenous control gene, $\beta 2$-microglobulin $)$, and $\Delta \Delta \mathrm{Ct}=(\Delta \mathrm{Ct}$ for target gene in test sample) - ( $\Delta \mathrm{Ct}$ for target gene in calibrator sample).

In vivo transplant into immunodeficient mice. The care and use of mice was carried out in accordance with the guidelines 
A

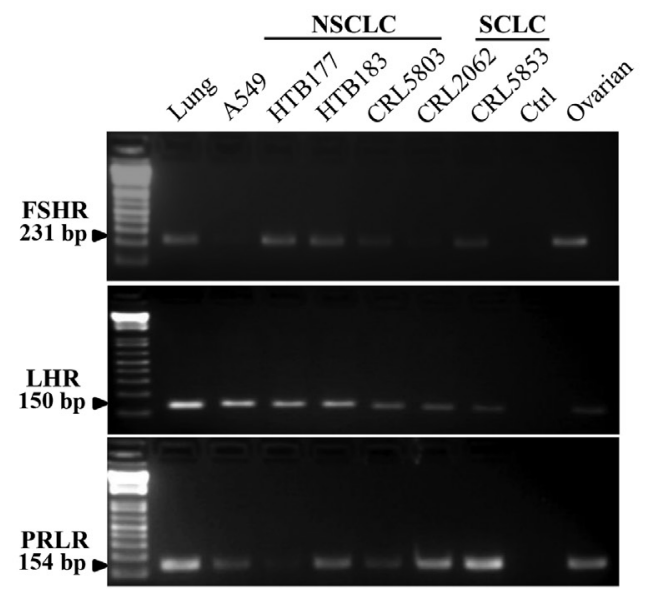

B

Ctrl FSH LH PRL

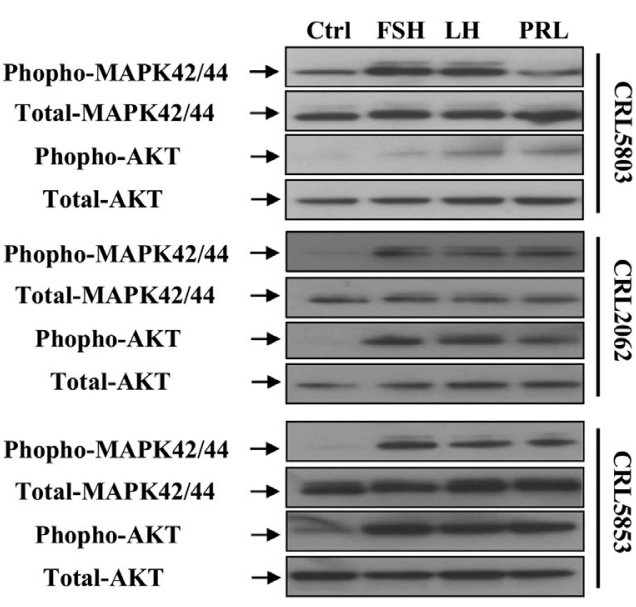

Figure 1. Human lung cancer cell lines express functional pituitary SexH receptors. (A) Expression of FSHR, LHR, and PRLR was detected in purified mRNA samples from both NSCLC cell lines (A549, HTB177, HTB183, and CRL5803) and SCLC cell lines (CRL2062 and CRL5853) by RT-PCR. Samples containing only water instead of cDNA and samples with cDNA purified from established human ovarian cancer cell lines were used in each run as negative and positive controls, respectively. Representative agarose gels of the RT-PCR amplicons are shown. (B) The effect of FSH, LH and PRL on phosphorylation of the intracellular pathway proteins p42/44 MAPK and AKT ${ }^{\text {ser } 473}$ in both NSCLC and SCLC cell lines was evaluated by western blot analysis. These cells were rendered quiescent by incubation for $6 \mathrm{~h}$ in RPMI- 1640 medium containing $0.5 \% \mathrm{BSA}$ at $37^{\circ} \mathrm{C}$, and afterwards the protein lysates were harvested after a 5 -min stimulation with FSH $(1 \mathrm{mU} / \mathrm{ml}), \mathrm{LH}(1 \mathrm{mU} / \mathrm{ml})$, PRL $(0.5 \mu \mathrm{g} / \mathrm{ml})$, or serum-free medium containing vehicle. The experiment was performed twice with similar results, and representative blots are shown. SexH, sex hormone; FSHR, FSH receptor; LHR, LH receptor; PRLR, PRL receptor; NSCLC, non-small cell lung cancer; SCLC, small cell lung cancer; RT-PCR, reverse transcription-polymerase chain reaction; FSH, follicle-stimulating hormone; LH, luteinizing hormone; PRL, prolactin; p42/44 MAPK, p42/44 mitogen-activated protein kinase; BSA, bovine serum albumin.

provided by the Institutional Animal Care and Use Committee of the University of Louisville, which conform to the Guide for the Care and Use of Laboratory Animals (Department of Health and Human Services, NIH publication no. 86-23). Prior to in vivo transplantation, CRL2062 and CRL5853 cells (10x10 per mouse) were treated ex vivo with vehicle only, $\mathrm{FSH}(1 \mathrm{mU} / \mathrm{ml})$, PRL $(0.5 \mu \mathrm{g} / \mathrm{ml})$, or CoPP IX chloride, a small-molecule HO-1 activator (50 $\mu \mathrm{mol} / 1$; Tocris Bioscience), for $2 \mathrm{~h}$ at $37^{\circ} \mathrm{C}$. In parallel, cells were also pre-treated with SB203580, a p38 MAPK inhibitor $(20 \mu \mathrm{mol} / \mathrm{l})$, for $6 \mathrm{~h}$ and were afterwards subjected to FSH or PRL for a further 2-h incubation at $37^{\circ} \mathrm{C}$. All cells were then washed and transplanted into severe combined immunodeficient (SCID)/beige inbred mice ( $\mathrm{n}=3$ per group), which were initially irradiated with $350 \mathrm{cGy} 24 \mathrm{~h}$ before transplantation. At $48 \mathrm{~h}$ post-transplantation, bone marrows, livers, and lungs were collected, and the presence of metastasized cancer cells (i.e., murine-human chimerism) was evaluated as described (25). Briefly, genomic DNA was purified from organs using the QIAamp DNA Mini kit (Qiagen, Inc.). Next, detection of human $\alpha$-satellite and murine $\beta$-actin DNA levels

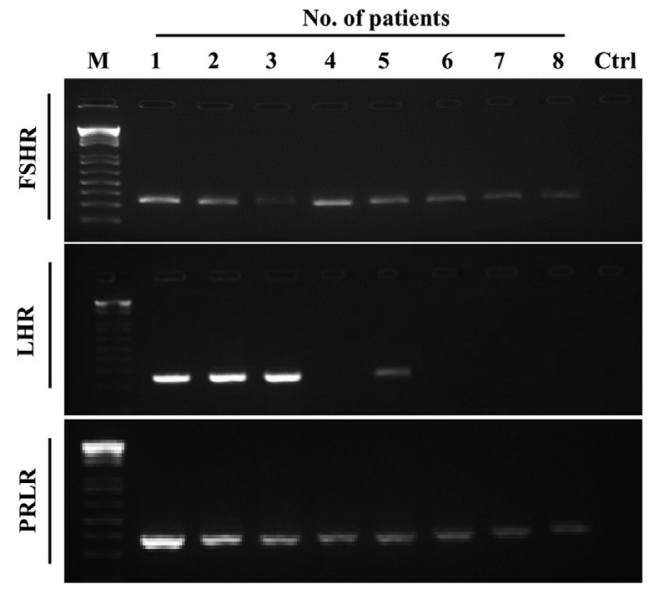

Figure 2. Primary human lung cancer cells express functional pituitary SexH receptors. Expression of FSHR, LHR, and PRLR was evaluated by RT-PCR in purified mRNA samples from primary cells obtained from human lung cancer patients $(n=8)$. A sample containing only water instead of cDNA was used as a negative control. Representative agarose gels of the RT-PCR amplicons are shown. SexH, sex hormone; FSHR, FSH receptor; LHR, LH receptor; PRLR, PRL receptor; RT-PCR, reverse transcription-polymerase chain reaction. 

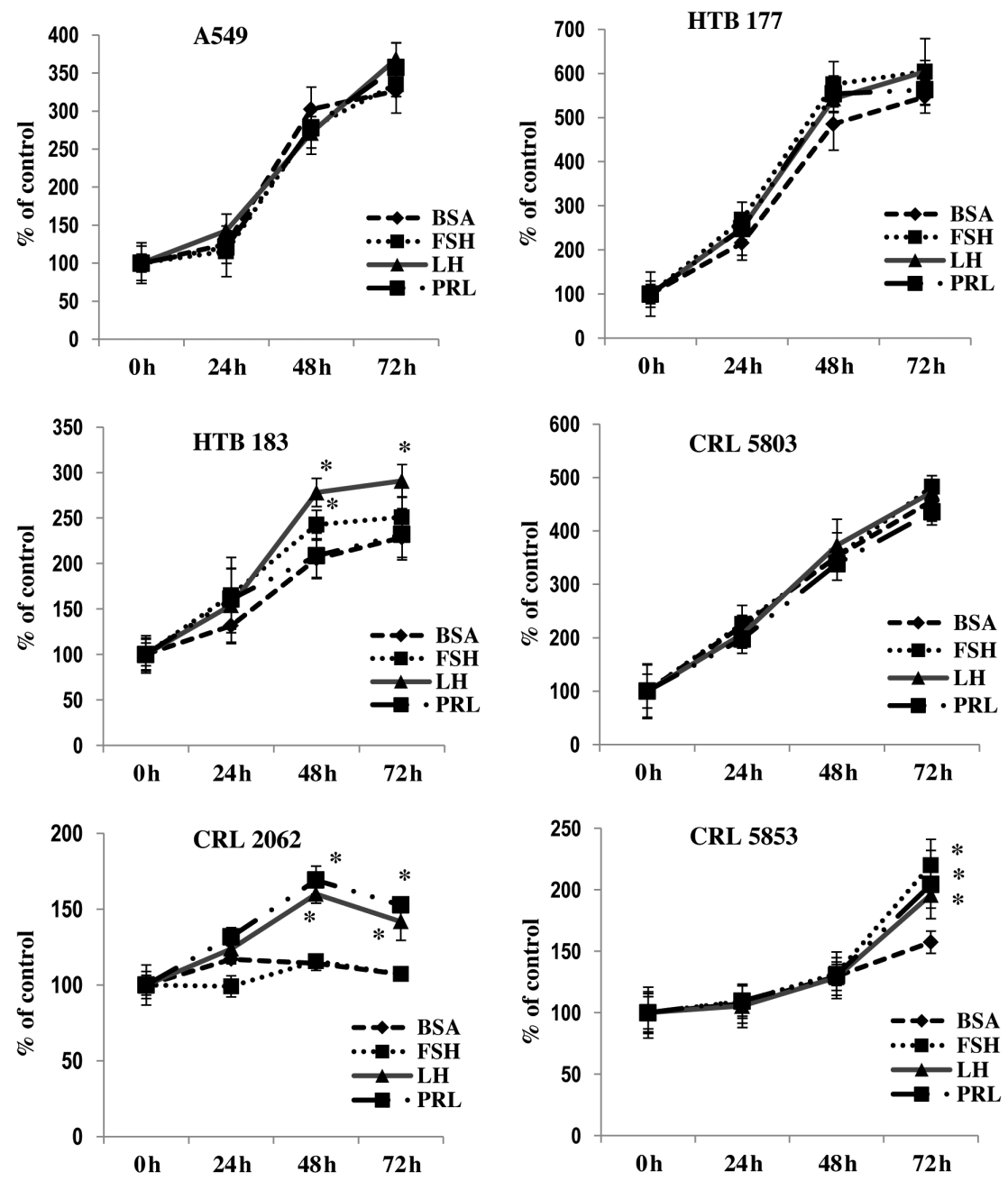

Figure 3. Human lung cancer cells proliferate in vitro in response to pituitary SexHs in a dose-dependent manner. All proliferation experiments were performed in RPMI-1640 culture medium containing 0.5\% (NSCLCs) or $0.2 \%$ (SCLCs) BSA for $72 \mathrm{~h}$ using $1.25 \times 10^{4}$ cells/well (NSCLCs) or 6x10 ${ }^{4}$ cells/well (SCLCs) in a 24-well plate. The negative control values are normalized to $100 \%$. For each cell line, the experiment was repeated twice in triplicate with similar results. For statistical comparisons, a one-way analysis of variance and a Tukey's test for post hoc analysis were carried out, and means \pm SD are shown. ${ }^{*} \mathrm{P} \leq 0.05$ vs. control. SexHs, sex hormones; NSCLCs, non-small cell lung cancers; SCLCs, small cell lung cancers; BSA, bovine serum albumin.

was carried out using real-time PCR and the ABI PRISM 7500 Fast Sequence Detection System (Applied Biosystems/Life Technologies). A $25-\mu 1$ reaction mixture containing $12.5 \mu 1$ SYBR-Green PCR Master Mix, 300 ng DNA template, and specific primers ( $\alpha$-satellite DNA sense, 5 '-ACCACTCTG TGTCCTTCGTTCG-3' and antisense, 5'-ACTGCGCTCTCA AAAGGAGTGT-3'; $\beta$-actin DNA sense, 5'-TTCAATTCCA ACACTGTCCTGTCT-3' and antisense, 5'-CTGTGGAGT GACTAAATGGAAACC-3') was used. Real-time PCR conditions for the amplification process were as follows: $95^{\circ} \mathrm{C}(15 \mathrm{sec})$; 40 cycles at $95^{\circ} \mathrm{C}(15 \mathrm{sec})$; and $60^{\circ} \mathrm{C}(1 \mathrm{~min})$. Samples without template controls were used in each run, and the $\Delta \mathrm{Ct}$ values were determined. For each cell line, the number of human cells present in the murine organs (the degree of chimerism) was calculated according to a standard curve generated by mixing different concentrations of human cells with a constant number of murine cells in a linear manner.

Data analysis. Statistical analysis was carried out using GraphPad Prism 6 software (GraphPad Software, Inc., La Jolla, CA, USA). All data are presented as means \pm SD. Statistical analysis of the data was done using one-way ANOVA and Tukey's test for post hoc pairwise multiple comparison. In all analyses $p \leq 0.05$ and $p \leq 0.01$ were considered significant.

\section{Results}

Human lung cancer cell lines express functional pituitary SexH receptors. We employed RT-PCR analysis to evaluate the expression of SexH receptors in four human NSCLC cell lines (A549, HTB177, HTB183, and CRL5803) and two SCLC cell lines (CRL2062 and CRL5853) and found that all these cell lines express FSH receptor (FSHR), PRL receptor (PRLR), and LH receptor (LHR) (Fig. 1A). We also found that in human lung cancer cell lines all these receptors responded to stimulation from pituitary SexHs by phosphorylation of p42/44 MAPK and AKT (Fig. 1B). Expression of these receptors was subsequently confirmed by immunofluorescence staining (data not shown).

Similarly, we were able to detect FSHR and PRLR mRNA in all eight patient NSCLC samples, and in four out of eight patients we also detected the expression of LHR mRNA (Fig. 2). 

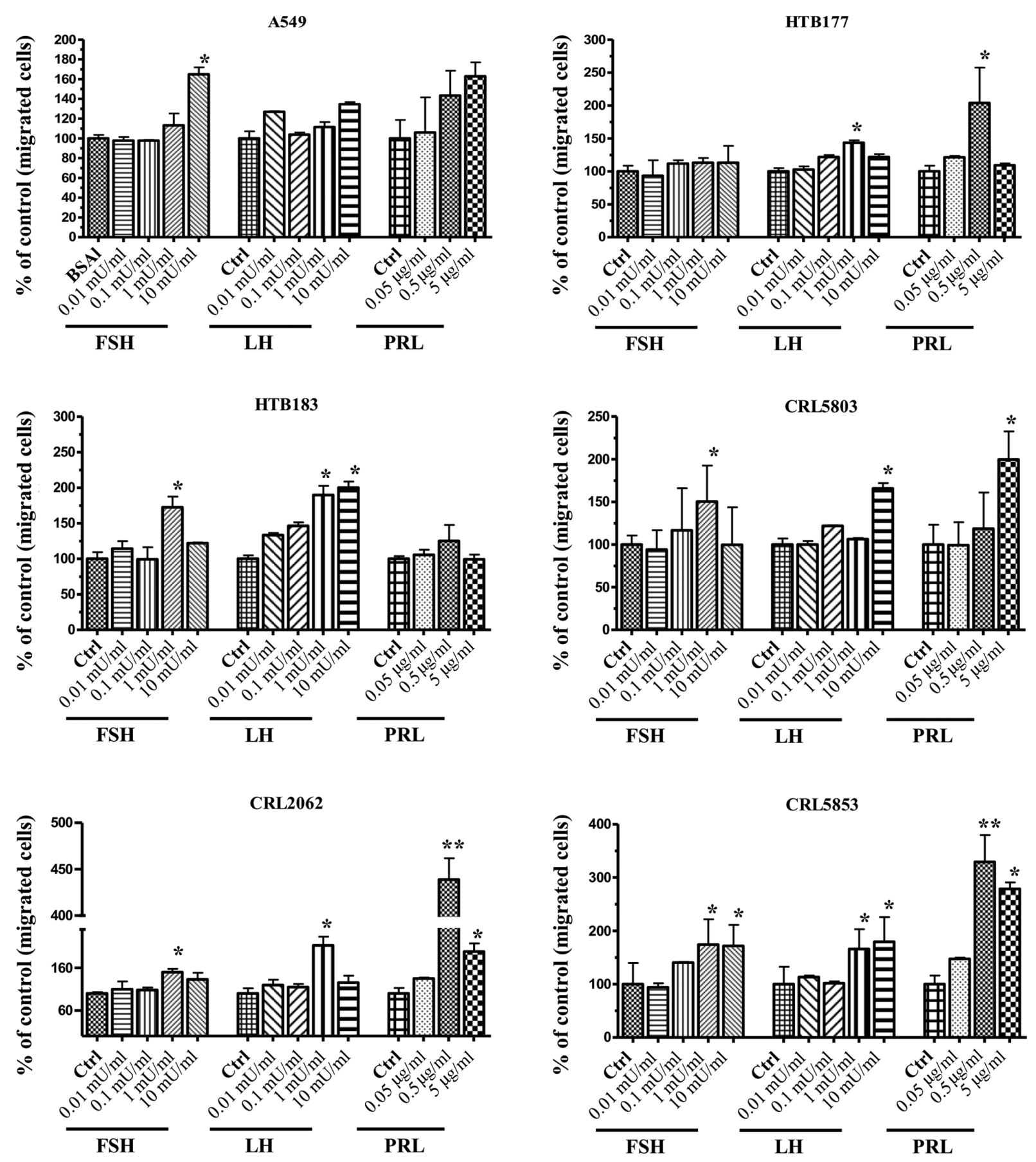

Figure 4. Pituitary SexHs stimulate the chemotaxis of human NSCLC and SCLC cell lines. Chemotaxis of NSCLC and SCLC cells through Transwell membranes $(8-\mu \mathrm{m}$ pore size) coated with $1 \%$ gelatin toward different concentrations of FSH $(0.01-10 \mathrm{mU} / \mathrm{ml}), \mathrm{LH}(0.01-10 \mathrm{mU} / \mathrm{ml})$, or PRL $(0.05-5 \mu \mathrm{g} / \mathrm{ml})$ was assessed. Before stimulation, cells were enzymatically dissociated by digestion with $0.25 \%$ trypsin and then rendered quiescent by incubation for $3 \mathrm{~h}$ in serum-free medium at $37^{\circ} \mathrm{C}$. All cell lines were also evaluated for migration in response to $10 \% \mathrm{FBS}$ and medium containing BSA as a positive and negative control, respectively. Twenty-four hours post-stimulation, loaded inserts were carefully removed, and the migrated cells were afterwards stained and counted using an inverted microscope. Data are extracted from at least triplicate samples from three independent experiments. Significance levels: $\mathrm{p} \leq 0.05$, ${ }^{* *} \mathrm{p} \leq 0.01$ vs. control (untreated) cells. SexHs, sex hormones; NSCLC, non-small cell lung cancer; SCLC, small cell lung cancer; FSH, follicle-stimulating hormone; LH, luteinizing hormone; PRL, prolactin; FBS, fetal bovine serum; BSA, bovine serum albumin.

Effect of pituitary SexHs on proliferation, migration, and adhesion of human lung cancer cell lines. To study the effect of pituitary SexHs on proliferation of lung cancer, we exposed lung cancer cell lines to FSH, LH, or PRL in serum-free medium supplemented with $0.5 \%$ BSA (Fig. 3). We found that one NSCLC cell line (HTB183) responded to stimulation by LH and FSH and that CRL2062, which is a SCLC cell line, responded to PRL or LH by proliferation, while another SCLC cell line (CRL5853) responded to all pituitary SexHs tested in our study.

In Transwell chemotaxis assays we found that lung cancer cell lines, to different degrees, responded to pituitary SexH gradients (Fig. 4). When we employed FSH as a chemoattractant, we observed a chemotactic response for three NSCLC 
A549

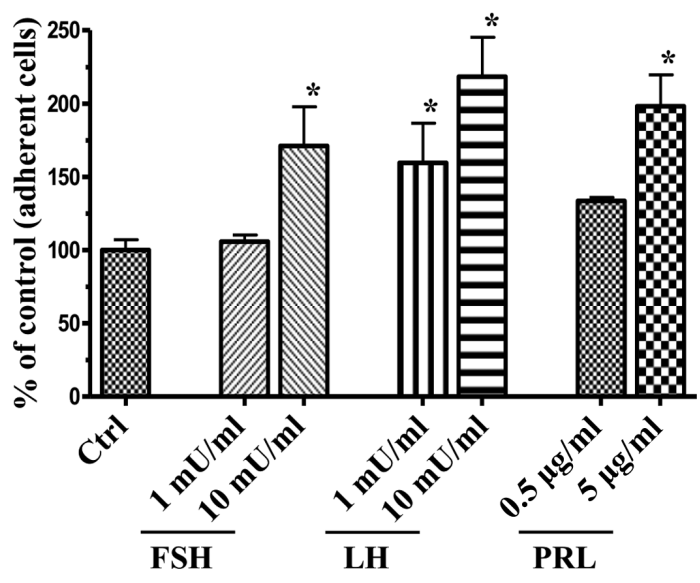

CRL2062

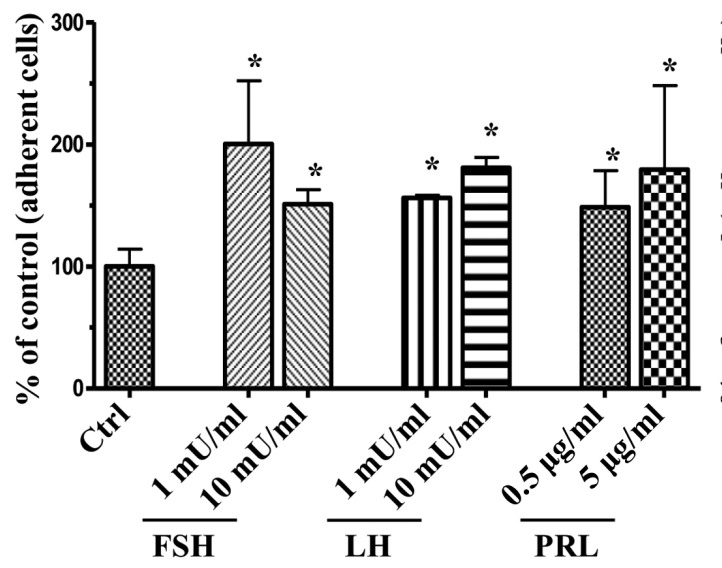

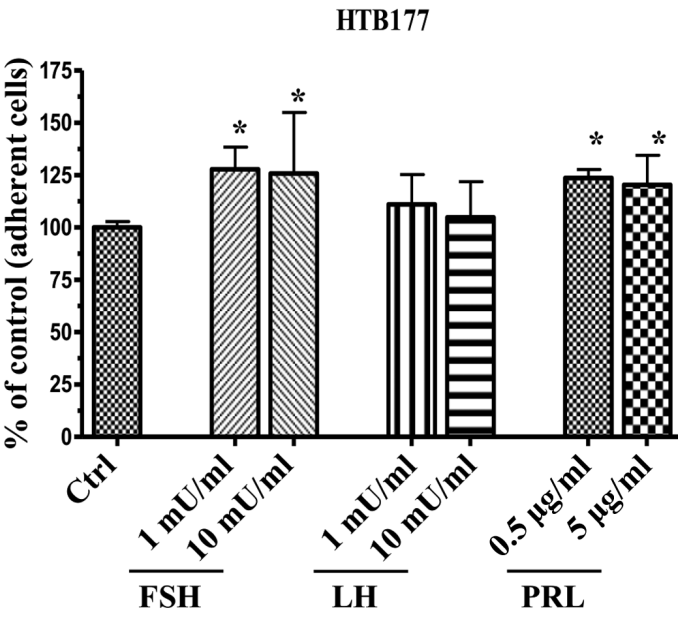

CRL5853

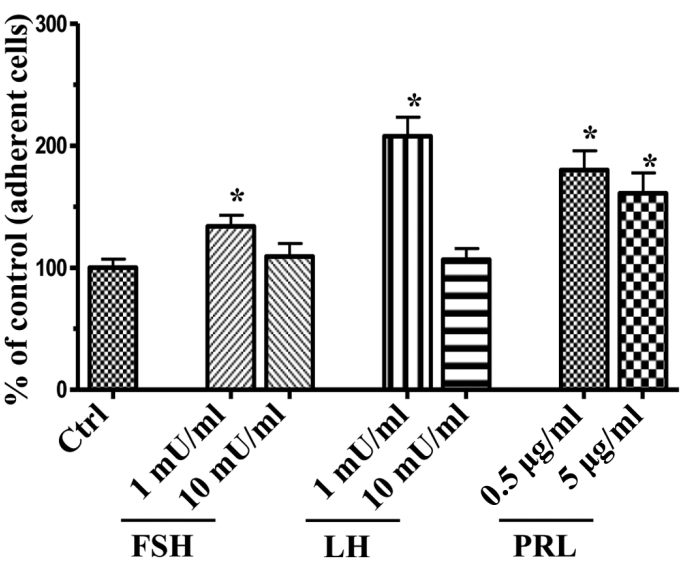

Figure 5. Pituitary SexHs promote the adhesiveness of human lung cancer to fibronectin. Adhesion of NSCLC (A549, HTB177) and SCLC (CRL2062, CRL5853) cells to fibronectin-coated surfaces in response to FSH (1-10 mU/ml), LH (1-10 mU/ml), or PRL $(0.05-5 \mu \mathrm{g} / \mathrm{ml})$. Quiescent cells $(5,000 \mathrm{cells} / 100 \mu \mathrm{l})$ were stimulated in medium containing BSA for a 5 -min incubation at $37^{\circ} \mathrm{C}$. After the non-adherent cells were removed via three consecutive washes with PBS, the number of adherent cells was directly scored by microscopic analysis. Cells were also evaluated for adhesion toward RPMI-1640 medium, with BSA as a negative control. Data are extracted from at least triplicate samples from three independent experiments. In all experiments, the negative control values are normalized to $100 \%$. Data are displayed as means \pm SD, with a statistical significance " $\mathrm{p} \leq 0.05$ between cells exposed to SexHs vs. control (unstimulated) cells. SexHs, sex hormones; NSCLC, non-small cell lung cancer; SCLC, small cell lung cancer; FSH, follicle-stimulating hormone; LH, luteinizing hormone; PRL, prolactin; BSA, bovine serum albumin.

cell lines (A549, HTB183, and CRL5803) and both SCLC cell lines (CRL2062, CRL5853). A significant responsiveness to LH was observed for the NSCLC cell lines HTB177, HTB183, and CRL5803 and both SCLC cell lines (CRL2062, CRL5853). Chemotactic responsiveness to PRL was particularly visible for both SCLC cell lines (CRL2062, CRL5853) as well as for A549, HTB177, and CRL5803 NSCLC cell lines.

In an adhesion assay (Fig. 5), we observed that pituitary SexHs, depending on the type of hormone and its dose, enhanced the adhesion of lung cancer cells to fibronectin-coated plates. The only exception was a non-significant effect of LH on the adhesion of HTB177 cells.

HO- 1 is a negative regulator of lung cancer cell migration. We recently reported that $\mathrm{HO}-1$ is a negative regulator of the migration of non-adherent cells and that the activity of $\mathrm{HO}-1$ is regulated by $\mathrm{p} 38 \mathrm{MAPK}$, which is a negative regulator of HO-1 expression (unpublished data). Here we asked whether the positive effect of pituitary SexHs on the migration of lung cancer cells could be explained by the downregulation of HO-1 and, based on the findings cited above, whether it corresponds with the upregulation of p38 MAPK.

To address this issue we stimulated both SCLC cell lines (CRL2062 and CRL5853), which respond robustly by chemotaxis to pituitary SexHs, and observed that FSH, LH, and PRL downregulate HO-1 expression in these cells, both at the mRNA and protein levels (Fig. 6A and B). Based on these findings, we exposed CRL5853 cells to FSH, LH, and PRL gradients to a small-molecule inhibitor (SnPP) and stimulator (CoPP) of HO-1 before chemotaxis (Fig. 6C). We found that, while the downregulation of HO-1 activity by SnPP enhanced the migratory response of lung cancer cells, an increase in HO-1 activity after exposure to CoPP led to a decrease in the migratory potential of these cells. This result demonstrated that $\mathrm{HO}-1$ negatively regulates migration not only for non-adherent cancer cells, as we demonstrated previously $(23,24)$, but also for adherent cancer cells. Moreover, a decrease in HO-1 activity after 

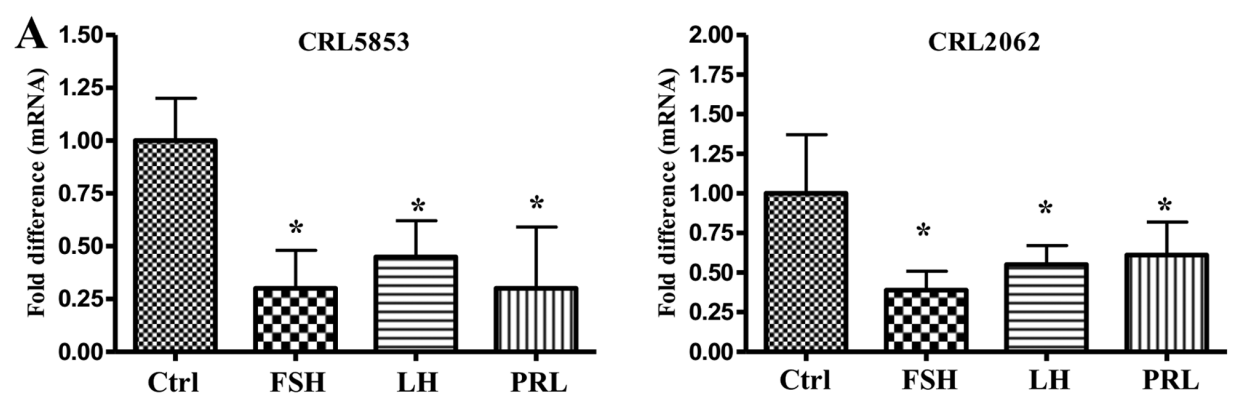

B CRL5853 CRL2062

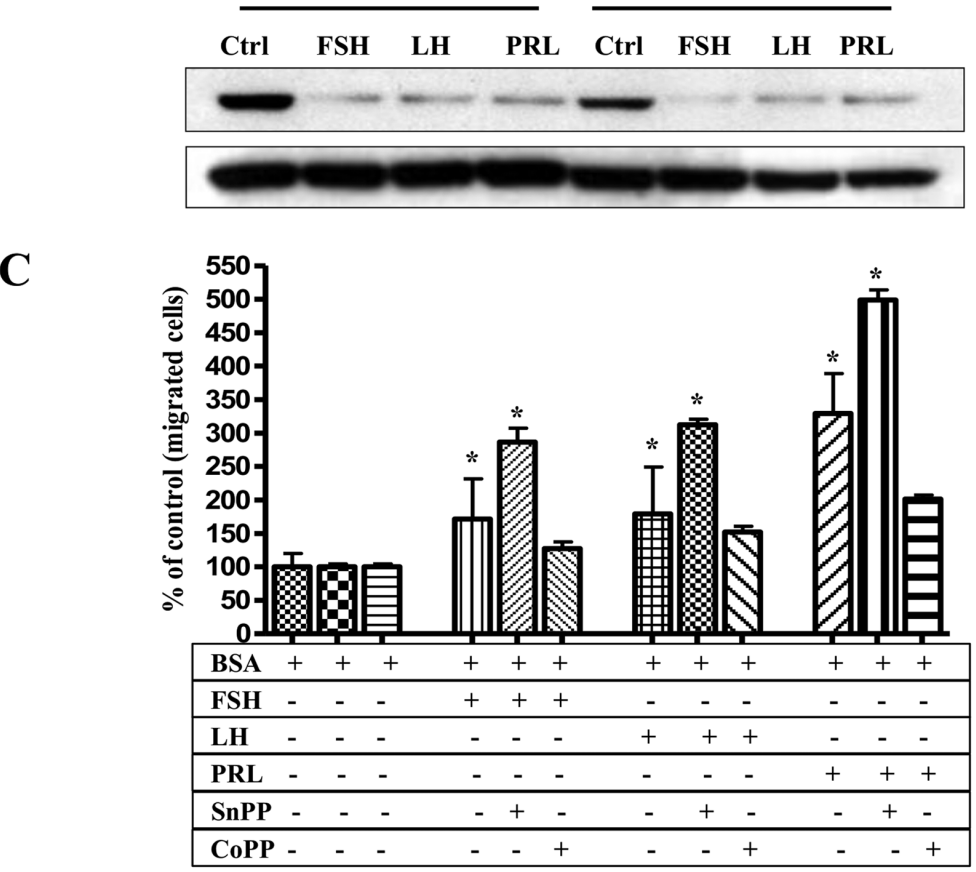

Figure 6. Pituitary SexHs enhance the migration of lung cancer cell by downregulation of HO-1. (A) RT-qPCR analysis of mRNA human HO-1 transcripts in mRNA samples purified from CRL5853 (left) and CRL2062 (right) cell lines cultured with FSH ( $1 \mathrm{mU} / \mathrm{ml}), \mathrm{LH}(1 \mathrm{mU} / \mathrm{ml})$, or PRL $(0.5 \mu \mathrm{g} / \mathrm{ml})$ in serum-free medium for $6 \mathrm{~h}$ at $37^{\circ} \mathrm{C} . \beta 2$-microglobulin was used as an endogenous control. Samples containing only water instead of cDNA were used in each run as a negative control. " $\mathrm{P} \leq 0.05$ is considered statistically significant between cells exposed to SexHs vs. unstimulated cells. (B) Western blot analysis of human HO-1 in protein lysates collected from CRL5853 and CRL2062 cell lines (70 $\mu \mathrm{g}$ per sample). After incubation of cells with these hormones at the doses indicated above, the protein was immediately extracted and afterwards quantified using the Pierce BCA Protein Assay kit and Multimode Analysis Software. In parallel, $\beta$-actin was also analyzed to ensure the equality of loading. Proteins extracted from cells cultured in assay medium only served as a control. (C) Chemotaxis of the CRL2062 cell line was also evaluated after inhibition or stimulation of HO-1 by incubation of cells with SnPP (50 $\mu \mathrm{mol} / 1)$ or CoPP (50 $\mu \mathrm{mol} / 1)$, respectively, in serum-free medium. Two hours later, the cells were then washed with PBS and evaluated for migration toward medium alone, FSH, LH, or PRL. The loaded inserts were afterwards carefully removed, and the migrated cells were stained and counted using an inverted microscope $24 \mathrm{~h}$ post-loading. Data are extracted from at least duplicate samples from three independent experiments. Significance is indicated by " $\mathrm{p} \leq 0.05$, where $p$ represents the statistical difference in migration between treated and untreated cells. SexHs, sex hormones; HO-1, heme oxygenase-1; RT-qPCR, quantitative real-time PCR; FSH, follicle-stimulating hormone; LH, luteinizing hormone; PRL, prolactin; SnPP, tin protoporphyrin; CoPP, cobalt protoporphyrin.

stimulation by SexH receptors correlated with upregulation of p38 MAPK (Fig. 8A).

Priming of lung cancer cells with pituitary SexHs enhances their in vivo seeding efficiency, and the stimulation of $\mathrm{HO}-\mathrm{I}$ by CoPP reverses this effect. To address the role of the in vivo effect of pituitary SexHs on the metastasis of lung cancer cells, we exposed both SCLC cell lines to FSH or PRL, and after incubation the cells were injected i.v. into immunodeficient NOD/SCID mice. Fig. 7 shows that the incubation of tumor cells before injection with FSH or PRL enhanced the seeding efficiency of lung cancer cells into bone marrow, liver, and lung.

Finally, we repeated this experiment with CRL2062 cells with the modification that, before priming with FSH or PRL, the cells were exposed to the small-molecule HO-1 activator CoPP or the small-molecule p38 MAPK inhibitor SB203580 (Fig. 8B). By upregulating HO-1 activity, both strategies decreased the seeding efficiency of lung cancer cells to the BM, liver, and lungs of immunodeficient mice.

\section{Discussion}

Evidence has accumulated that several types of malignancies share certain markers with germ cells and respond to stimulation by SexHs (1,4-6). In support of this connection, some tumors express pluripotency markers (e.g., Oct-4), secrete carcinoembryonic antigen (CEA), express cancer-testis antigens (CTAs), and respond by proliferation after stimulation 

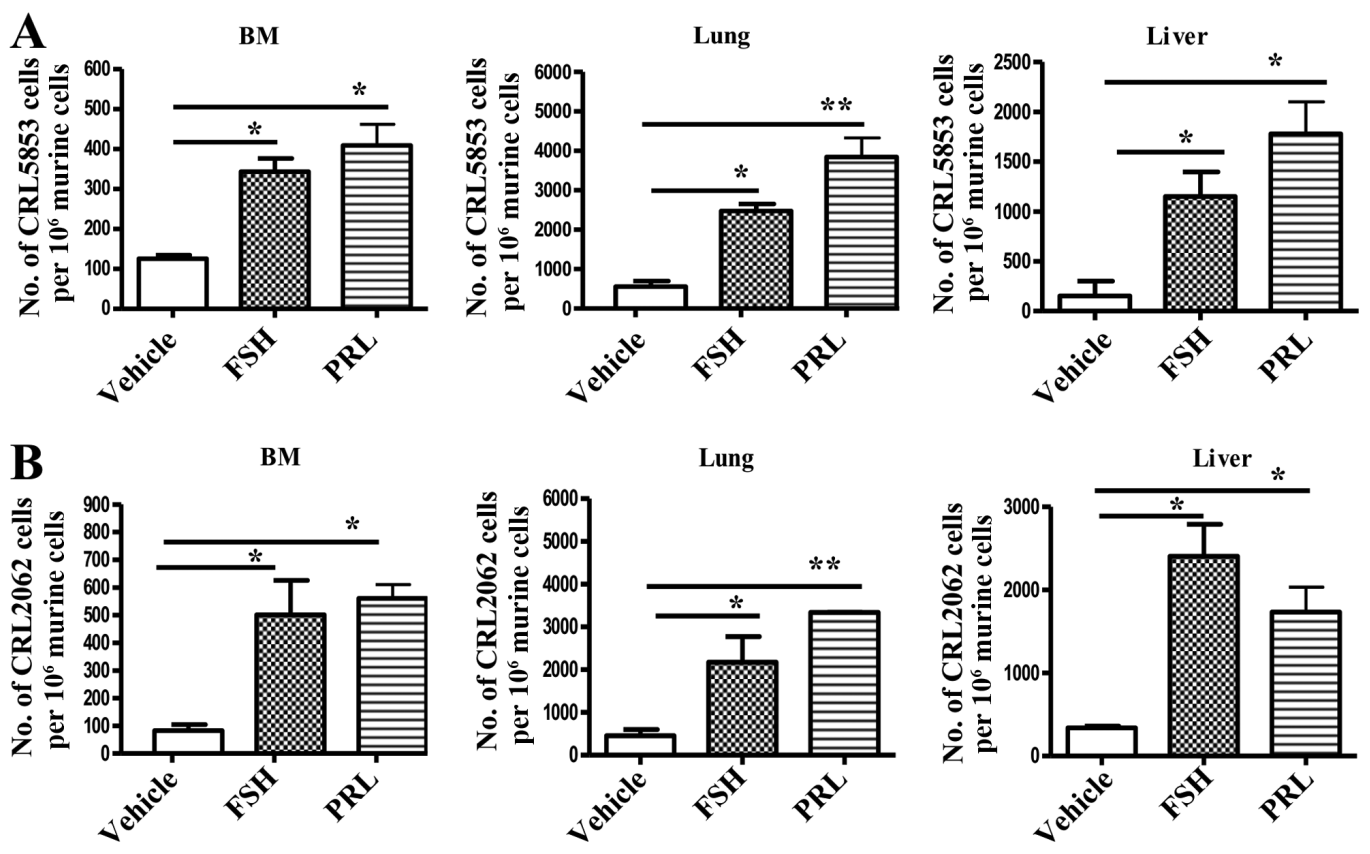

Figure 7. Pituitary SexHs accelerate the metastasis of lung cancer cells in vivo. Detection of transplanted human (A) CRL5853 and (B) CRL2062 cells $\left(1 \times 10^{5}\right.$ cells/mouse) in the organs of irradiated (SCID)/beige inbred mice post in vivo transplantation. Pre-implantation, the cells were incubated ex vivo with vehicle only, FSH $(1 \mathrm{mU} / \mathrm{ml})$, or PRL $(0.5 \mu \mathrm{g} / \mathrm{ml})$ for $2 \mathrm{~h}$. Under all conditions, serum-free medium was used. Detection of human cells in BM, lung, and liver was evaluated by RT-qPCR for the presence of human Alu sequences in purified genomic DNA samples. Significance levels are indicated by ${ }^{*} \mathrm{p} \leq 0.05$, *" $\leq 0.01$ vs. untreated cells. SexHs, sex hormones; SCID, severe combined immunodeficient; FSH, follicle-stimulating hormone; PRL, prolactin; RT-qPCR, quantitative real-time PCR.

by both pituitary and gonadal SexHs (26-30). Interestingly, it has been reported that human lung cancer cells may express Oct-4, CEA, as well as several CTAs, including Sp17, PTTG1, and AKAP-4, at the protein level. However, it is known that the expression of these markers may vary between histological subtypes of lung cancer (SCLC vs. NSCLC).

We became interested in the question of whether human lung cancer cell lines express pituitary SexH receptors and whether they respond to stimulation by FSH, LH, or PRL. The lung cancer cell lines investigated in this study as well as tumor cells from lung cancer patients all express pituitary SexH mRNAs. Moreover, studies performed with human cancer cell lines demonstrated that these receptors are functional. What is intriguing, some of the lung cancer cell lines responded to SexHs by enhanced proliferation. This observation suggests that pituitary SexH therapy should be avoided in lung cancer patients, even if they have achieved stable remission. Based on our results, there is a risk that such treatment could activate dormant cancer cells.

There is another important question related to this topic. One could ask whether elevated SexH levels could contribute to lung cancer development as has been postulated in other types of malignancies such as breast or ovarian cancer $(1,31)$. Lung cancer incidence increases with age, and it is well known that the FSH level also increases with age as a compensatory feedback loop in response to a decrease in gonadal function $(12,14)$. However, this hypothetical causal relationship requires more direct experimental evidence and well-designed epidemiological studies. On the other hand, while SCLC cells may produce some hormones ectopically as part of the endocrine paraneoplastic syndrome, they usually secrete other hormones such as adrenocorticotropic hormone (ACTH) or PTH $(9,32)$. Thus, the effect of SexHs on lung cancer cell growth seems not to be autocrine but rather of an endocrine nature.

We also found that, in addition to pro-proliferative effects, pituitary SexHs chemoattract lung cancer cells and increase their adhesion. These results are supported by clinical observations showing that lung cancer cells may metastasize to PRL-producing pituitary adenomas $(33,34)$. In fact, in our studies PRL was the most potent of all pituitary SexHs in chemottracting SCLC cells. Additional evidence supporting a pro-metastatic effect of pituitary SexHs on lung cancer cells are in vivo results showing that a short exposure of these cells ex vivo to pituitary SexHs enhances their seeding efficiency in $\mathrm{BM}$, liver, and lung in an immunodeficient mouse model.

Lung cancer cells may respond by chemotaxis to several factors; therefore, an anti-metastatic strategy to block only one type of receptor would be of very limited benefit. Thus, while designing an anti-metastatic strategy, it is more important to look for a molecular target that is employed by other pro-metastatic factors (e.g., chemokines or certain pro-metastatic growth factors). To address this issue, we have recently determined that upregulation of the stress-induced enzyme $\mathrm{HO}-1$ is an efficient method for inhibiting cell migration $(23,24)$. In support of this finding in the current study, the enhanced chemotaxis of lung cancer cell lines in response to FSH, LH, and PRL gradients corresponded with decreases in HO-1 activity. Based on this observation, we tested CoPP, a small-molecule stimulator of HO-1, as a means to inhibit migration of lung cancer cells in both in vitro and in vivo models and found that exposure to CoPP significantly inhibited the trafficking of lung cancer cells.

This strategy has an obvious advantage, since upregulation of HO-1 in tumor cells will simultaneously decrease their migratory responsiveness to other pro-metastatic factors 
A

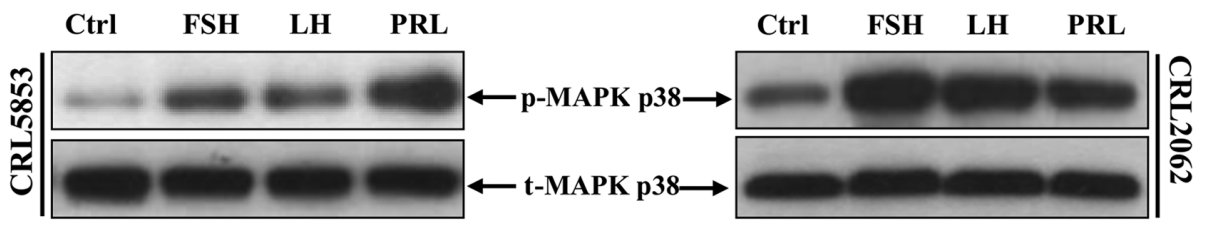

B
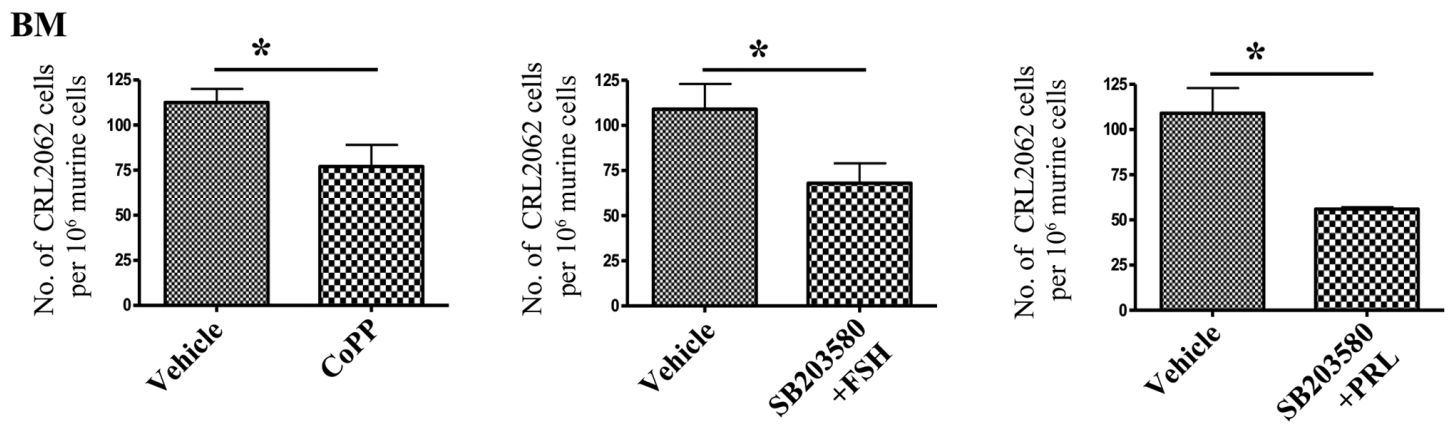

\section{Liver}
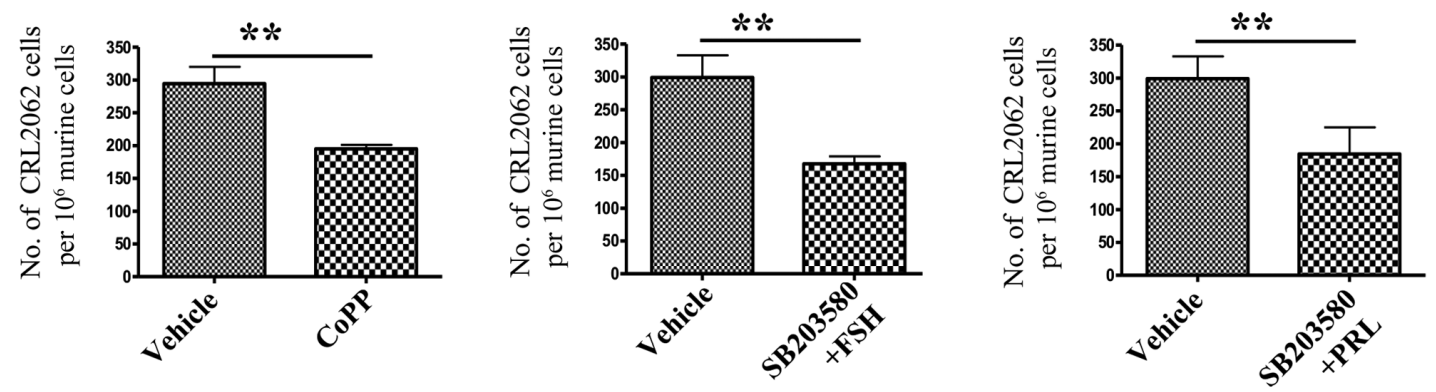

\section{Lung}
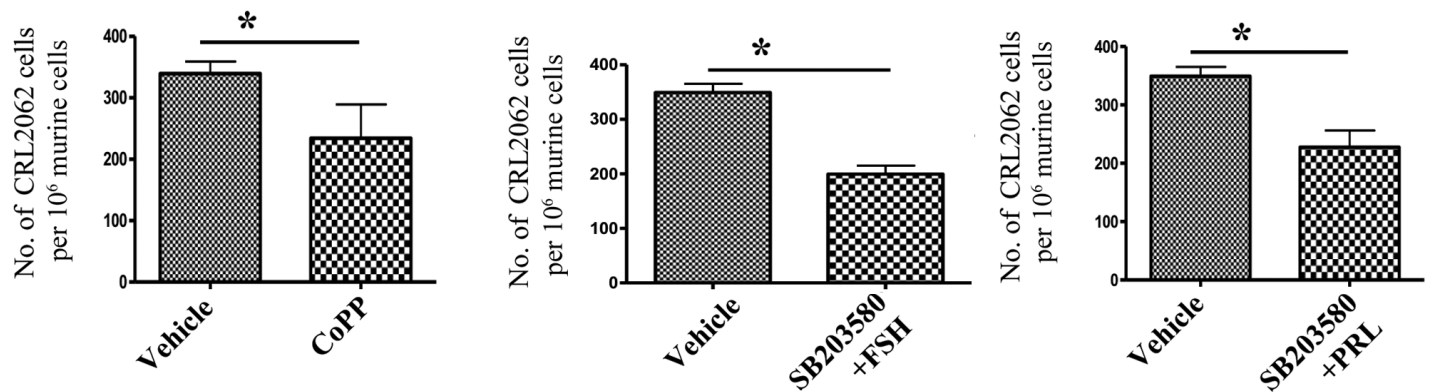

Figure 8. Pituitary SexHs enhance the migration of lung cancer cells through phosphorylation of p38 MAPK-dependent downregulation of HO-1. (A) Western blot analysis of phospho-p38 MAPK in protein lysates collected from quiescent CRL5853 (left) and CRL2062 (right) lung cancer cell lines. Cells were stimulated with $0.5 \% \mathrm{BSA}$ in appropriate medium, FSH, LH, or PRL for $5 \mathrm{~min}$ at $37^{\circ} \mathrm{C}$. Total p38 MAPK was also analyzed to ensure equal protein loading in all lanes. (B) Evaluation of the spread of transplanted lung cells (CRL2062) in vivo after stimulation of HO-1 levels via pre-incubation of cells with the HO-1 activator $\mathrm{CoPP}(50 \mu \mathrm{mol} / \mathrm{l})$ for $2 \mathrm{~h}$ at $37^{\circ} \mathrm{C}$. In parallel, cells were also pre-treated with SB203580, a p38 MAPK inhibitor (20 $\mu$ mol/l), for $6 \mathrm{~h}$ and subsequently subjected to FSH $(1 \mathrm{mU} / \mathrm{ml})$ or PRL $(0.5 \mu \mathrm{g} / \mathrm{ml})$ for a further $2 \mathrm{~h}$. Forty-eight hours after in vivo transplantation into irradiated immunodeficient (SCID)/beige inbred mice ( $1 \times 10^{6}$ cells/mouse), the organs were harvested, and detection and quantification of the human cells were then analyzed by RT-qPCR. Significance levels are indicated by ${ }^{*} \mathrm{p} \leq 0.05,{ }^{* *} \mathrm{p} \leq 0.01$ vs. untreated cells (vehicle only). SexHs, sex hormones; HO-1, heme oxygenase-1; BSA, bovine serum albumin; FSH, follicle-stimulating hormone; LH, luteinizing hormone; PRL, prolactin; CoPP, cobalt protoporphyrin; SCID, severe combined immunodeficient; RT-qPCR, quantitative real-time PCR.

besides SexHs, such as SDF-1 or HGF/SF. Moreover, since HO-1 is positively regulated in a 338 MAPK-dependent manner, we also employed SB203580, a small-molecule inhibitor of p38 MAPK, and observed a similar anti-metastatic effect. Therefore, we believe that our observations generated with CoPP and SB203580 are highly relevant for developing new anti-metastatic strategies.

These investigations also have another implication. Namely, since pituitary SexH receptors are expressed by cells from the germ lineage beginning at the very early stages of embryogenesis $(35,36)$, and, as demonstrated in this study, lung cancer cells also express pituitary SexH receptors, there may be a developmental link between these cells, as suggested at the beginning of this section. Interestingly, 150 years ago Virchow (37) and Cohnheim (38) proposed that some malignancies develop from dormant embryonic or germ cells residing in adult tissues. We have recently reported the existence of very small embryonic-like stem cells (VSELs), which 
express several embryonic/germline markers residing in adult tissues, including lung tissue (27,39-41). One can speculate that these or closely related cells could theoretically be the source of some tumors. In support of this possibility, VSELs express several SexH receptors as well as genes involved in primordial germ cell development $(35,36,39,41)$. This working hypothesis, however, requires more experimental evidence.

Finally, it is well known that the persistent activation of the hypothalamic-pituitary-adrenal (HPA) axis as seen for example in the chronic stress response and in depression may impair the immune response and contribute to the development and progression of some types of cancer (42). Our data indicate that in endocrine system in addition to ACTH also SexH may play an important role. Based on this, more study is needed on the bidirectional communication between the endocrine and immune systems for the development of a new clinical and treatment strategies.

In conclusion, lung cancer cells are responsive to pituitary SexH stimulation, and these hormones may play an important role in lung cancer progression and metastasis. However, more experimental work is needed to see whether an increased level of pituitary SexHs with age correlates with a predisposition to lung cancer development. Finally, we propose that upregulation of HO-1 and downregulation of p38 MAPK by small-molecule modulators may provide the basis for new anti-metastatic strategies for lung cancer patients.

\section{Acknowledgements}

This study was supported by NIH grants 2R01 DK074720 and R01HL112788, the Stella and Henry Endowment, and NCN Harmonia grant UMO-2014/14/M/NZ3/00475 to M.Z.R., and OPUS grant UMO-2016/21/B/NZ4/00201 to M.K.

\section{References}

1. van Kruchten M, van der Marel P, de Munck L, Hollema $H$ Arts H, Timmer-Bosscha H, de Vries E, Hospers G and Reyners A: Hormone receptors as a marker of poor survival in epithelial ovarian cancer. Gynecol Oncol 138: 634-639, 2015.

2. García-Cruz E, Piqueras M, Huguet J, Peri L, Izquierdo L, Musquera M, Franco A, Alvarez-Vijande R, Ribal MJ and Alcaraz A: Low testosterone levels are related to poor prognosis factors in men with prostate cancer prior to treatment. BJU Int 110: E541-E546, 2012.

3. García-Cruz E, Piqueras M, Ribal MJ, Huguet J, Serapiao R, Peri L, Izquierdo L and Alcaraz A: Low testosterone level predicts prostate cancer in re-biopsy in patients with high grade prostatic intraepithelial neoplasia. BJU Int 110: E199-E202, 2012.

4. García-Cruz E, Carrión Puig A, García-Larrosa A, Sallent A, Castañeda-Argáiz R, Piqueras M, Ribal MJ, Leibar-Tamayo A, Romero-Otero J and Alcaraz A: Higher sex hormone-binding globulin and lower bioavailable testosterone are related to prostate cancer detection on prostate biopsy. Scand J Urol 47 282-289, 2013.

5. Lønning PE: Poor-prognosis estrogen receptor-positive disease: Present and future clinical solutions. Ther Adv Med Oncol 4: 127-137, 2012.

6. Poniewierska-Baran A, Schneider G, Sun W, Abdelbaset-Ismail A, Barr FG and Ratajczak MZ: Human rhabdomyosarcoma cells express functional pituitary and gonadal sex hormone receptors: Therapeutic implications. Int J Oncol 48: 1815-1824, 2016.

7. Abdelbaset-Ismail A, Borkowska S, Janowska-Wieczorek A, Tonn T, Rodriguez C, Moniuszko M, Bolkun L, Koloczko J, Eljaszewicz A, Ratajczak J, et al: Novel evidence that pituitary gonadotropins directly stimulate human leukemic cells-studies of myeloid cell lines and primary patient AML and CML cells Oncotarget 7: 3033-3046, 2016.
8. Taggart DP, Gray CE, Bowman A, Faichney A and Davidson KG: Serum androgens and gonadotrophins in bronchial carcinoma. Respir Med 87: 455-460, 1993.

9. Huchon G and Akoun G: Endocrine secretions by bronchial tumors. Sem Hop 55: 180-188, 1979 (In French).

10. Siraj A, Desestret V, Antoine M, Fromont G, Huerre M, Sanson M, Camparo P, Pichon C, Planeix F, Gonin J, et al: Expression of follicle-stimulating hormone receptor by the vascular endothelium in tumor metastases. BMC Cancer 13: 246, 2013.

11. Chen M, Xu Y, Hao X, Zhang Y, Xu W and Lu B: The significance of serum sexual hormones' level in male patients with lung cancer. Zhongguo Fei Ai Za Zhi 8: 300-303, 2005 (In Chinese).

12. Klein NA, Illingworth PJ, Groome NP, McNeilly AS, Battaglia DE and Soules MR: Decreased inhibin B secretion is associated with the monotropic FSH rise in older, ovulatory women: A study of serum and follicular fluid levels of dimeric inhibin A and B in spontaneous menstrual cycles. J Clin Endocrinol Metab 81: 2742-2745, 1996.

13. Wang YJ, Wu JC, Lee SD, Tsai YT and Lo KJ: Gonadal dysfunction and changes in sex hormones in postnecrotic cirrhotic men: A matched study with alcoholic cirrhotic men. Hepatogastroenterology 38: 531-534, 1991.

14. Aasebø U, Bremnes RM, de Jong FH, Aakvaag A and Slørdal L: Pituitary-gonadal dysfunction in male patients with lung cancer. Association with serum inhibin levels. Acta Oncol 33: 177-180, 1994.

15. Parkin DM, Bray F, Ferlay J and Pisani P: Global cancer statistics, 2002. CA Cancer J Clin 55: 74-108, 2005.

16. Molina JR, Yang P, Cassivi SD, Schild SE and Adjei AA: Non-small cell lung cancer: Epidemiology, risk factors, treatment, and survivorship. Mayo Clin Proc 83: 584-594, 2008.

17. Mulshine JL, Treston AM, Brown PH, Birrer MJ and Shaw GL: Initiators and promoters of lung cancer. Chest 103 (Suppl): 4S-11S, 1993

18. Schnabel PA and Junker K: Neuroendocrine tumors of the lungs. From small cell lung carcinoma to diffuse idiopathic pulmonary neuroendocrine cell hyperplasia. Pathologe 35: 557-564, 2014 (In German).

19. Chen Z, Fillmore CM, Hammerman PS, Kim CF and Wong KK: Non-small-cell lung cancers: A heterogeneous set of diseases. Nat Rev Cancer 14: 535-546, 2014.

20. Idowu MO and Powers CN: Lung cancer cytology: Potential pitfalls and mimics - a review. Int J Clin Exp Pathol 3: 367-385, 2010.

21. Hall A: The cytoskeleton and cancer. Cancer Metastasis Rev 28: $5-14,2009$.

22. Caswell P and Norman J: Endocytic transport of integrins during cell migration and invasion. Trends Cell Biol 18: 257-263, 2008

23. Adamiak M, Iv JB, Zhao J, Abdelbaset-Ismail A, Grubczak K, Borkowska S, Wysoczynski M and Ratajczak MZ: Downregulation of heme oxygenase 1 (HO-1) activity in hematopoietic cells enhances their engraftment after transplantation. Cell Transplant: Oct 16, 2015 (Epub ahead of print).

24. Wysoczynski M, Ratajczak J, Pedziwiatr D, Rokosh G, Bolli R and Ratajczak MZ: Identification of heme oxygenase 1 (HO-1) as a novel negative regulator of mobilization of hematopoietic stem/progenitor cells. Stem Cell Rev 11: 110-118, 2015.

25. Abdelbaset-Ismail A, Pedziwiatr D, Suszyńska E, SluczanowskaGlabowska S, Schneider G, Kakar SS and Ratajczak MZ: Vitamin D3 stimulates embryonic stem cells but inhibits migration and growth of ovarian cancer and teratocarcinoma cell lines. J Ovarian Res 9: 26, 2016.

26. Bhatt S, Stender JD, Joshi S, Wu G and Katzenellenbogen BS: OCT-4: A novel estrogen receptor- $\alpha$ collaborator that promotes tamoxifen resistance in breast cancer cells. Oncogene: Apr 11, 2016 (Epub ahead of print).

27. Ratajczak MZ, Shin DM and Kucia M: Very small embryonic/epiblast-like stem cells: A missing link to support the germ line hypothesis of cancer development? Am J Pathol 174: 1985-1992, 2009

28. Sławek S, Szmyt K, Fularz M, Dziudzia J, Boruczkowski M, Sikora J and Kaczmarek M: Pluripotency transcription factors in lung cancer - a review. Tumour Biol 37: 4241-4249, 2016.

29. Reiter MJ, Costello JE, Schwope RB, Lisanti CJ and Osswald MB: Review of commonly used serum tumor markers and their relevance for image interpretation. J Comput Assist Tomogr 39: $825-834,2015$. 
30. Zhang W, Barger CJ, Link PA, Mhawech-Fauceglia P, Miller A, Akers SN, Odunsi K and Karpf AR: DNA hypomethylation-mediated activation of Cancer/Testis Antigen 45 (CT45) genes is associated with disease progression and reduced survival in epithelial ovarian cancer. Epigenetics 10: 736-748, 2015.

31. Key TJ, Appleby PN, Reeves GK, Travis RC, Alberg AJ, Barricarte A, Berrino F, Krogh V, Sieri S, Brinton LA, et al; Endogenous Hormones and Breast Cancer Collaborative Group: Sex hormones and risk of breast cancer in premenopausal women A collaborative reanalysis of individual participant data from seven prospective studies. Lancet Oncol 14: 1009-1019, 2013.

32. Sorenson GD, Pettengill OS, Brinck-Johnsen T, Cate CC and Maurer LH: Hormone production by cultures of small-cell carcinoma of the lung. Cancer 47: 1289-1296, 1981.

33. Rotondo F, Kovacs K, Macdonald RL, Prud'homme GJ, Latta E and Munoz D: Non-small cell bronchial carcinoma metastasizing into a prolactin-producing pituitary adenoma. Int J Surg Pathol 21: 68-71, 2013.

34. Hanna FW, Williams OM, Davies JS, Dawson T, Neal J and Scanlon MF: Pituitary apoplexy following metastasis of bronchogenic adenocarcinoma to a prolactinoma. Clin Endocrinol (Oxf) 51: 377-381, 1999.

35. Abdelbaset-Ismail A, Suszynska M, Borkowska S, Adamiak M, Ratajczak J, Kucia M and Ratajczak MZ: Human haematopoietic stem/progenitor cells express several functional sex hormone receptors. J Cell Mol Med 20: 134-146, 2016.
36. Mierzejewska K, Borkowska S, Suszynska E, Suszynska M, Poniewierska-Baran A, Maj M, Pedziwiatr D, Adamiak M, Abdel-Latif A, Kakar SS, et al: Hematopoietic stem/progenitor cells express several functional sex hormone receptors - novel evidence for a potential developmental link between hematopoiesis and primordial germ cells. Stem Cells Dev 24: 927-937, 2015.

37. Virchow R: Editorial Archive fuer pathologische. Anatomie und Physiologie fuer klinische Medizin 8: 23-54, 1855 (In German).

38. Conheim J: Congenitales, quergestreiftes muskelsarkon der nireren. Virchows Arch 65: 64-69, 1875 (In German).

39. Ratajczak MZ, Shin DM, Liu R, Marlicz W, Tarnowski M, Ratajczak J and Kucia M: Epiblast/germ line hypothesis of cancer development revisited: Lesson from the presence of Oct- $4^{+}$cells in adult tissues. Stem Cell Rev 6: 307-316, 2010.

40. Ratajczak MZ, Zuba-Surma EK, Wysoczynski M, Ratajczak J and Kucia M: Very small embryonic-like stem cells: Characterization, developmental origin, and biological significance. Exp Hematol 36: 742-751, 2008.

41. Shin DM, Liu R, Klich I, Wu W, Ratajczak J, Kucia M and Ratajczak MZ: Molecular signature of adult bone marrow-purified very small embryonic-like stem cells supports their developmental epiblast/germ line origin. Leukemia 24: 1450-1461, 2010.

42. Reiche EM, Nunes SO and Morimoto HK: Stress, depression, the immune system, and cancer. Lancet Oncol 5: 617-625, 2004. 